\title{
BMG Global Heath Vaccinating the world against COVID-19: getting the delivery right is the greatest challenge
}

\author{
Rima Shretta (D) , ${ }^{1}$ Nathaniel Hupert, ${ }^{2,3}$ Patrick Osewe, ${ }^{4}$ Lisa J White ${ }^{1,3}$
}

To cite: Shretta R, Hupert N, Osewe P, et al. Vaccinating the world against COVID-19: getting the delivery right is the greatest challenge. BMJ Global Health 2021;6:e005273. doi:10.1136/ bmjgh-2021-005273

Received 4 February 2021 Revised 11 February 2021 Accepted 15 February 2021

\section{Check for updates}

(C) Author(s) (or their employer(s)) 2021. Re-use permitted under CC BY-NC. No commercial re-use. See rights and permissions. Published by BMJ.

${ }^{1}$ Nuffield Department of Medicine, University of Oxford, Oxford, UK

${ }^{2}$ Weill Cornell Medicine and Cornell Institute for Disease and Disaster Preparednes, New York NY, USA

${ }^{3}$ CoMo Consortium, University of Oxford, Oxford, UK

${ }^{4}$ Asian Development Bank, Mandaluyong City, Philippines

Correspondence to

Dr Rima Shretta;

rima.shretta@ndm.ox.ac.uk
Mass vaccination against COVID-19 is considered to be the most effective strategy to bring the SARS-COV-2/COVID-19 pandemic under control. In an unprecedented global scientific effort, 11 vaccines have already been authorised for full or emergency use in at least one country, and 84 countries or locations have begun their roll-out to priority populations. ${ }^{1}$

However, despite the advanced healthcare infrastructure and logistical capacity in high-income countries (HIC), implementation has been slow. ${ }^{2}$ In the United States, by 2 March, 23.7 doses/100 population had been administered, less than $80 \%$ of those distributed. Countries in Europe have also faced delays - France and Italy have administered 7 doses/100 and 7.6/100 population respectively. ${ }^{2}$ Recognition is growing that vaccinating the global population against COVID-19, particularly those in low and middle-income countries (LMIC), will be the largest global peacetime logistical effort ever undertaken, requiring unprecedented government/industry collaboration across distinct administrative, business, medical and information infrastructures. In fact, cost may be the least daunting hurdle to accomplishing this Herculean task.

Existing vaccine supply chains are carefully coordinated orchestrations involving multiple parties and parts. To provide global coverage of an estimated 15 billion doses, up to 200000 pallet shipments and 15 million deliveries, as well as 15000 freighter flights will be required across the various supply chains. ${ }^{3}$ Pfizer (Pfizer-BioNTech COVID-19 vaccine) expects an average of 20 daily cargo flights worldwide which will need to be coordinated with regional and local transport sources to minimise product delays. In LMICs, particularly in rural areas, transport links are slower and medical facilities are less equipped. The development of a COVID-19 vaccine-specific supply chain may adversely affect other supply chains. For example, air cargo carriers may favour the distribution of the new vaccines because of more secure payment guarantees. A concerted effort to avoid causing delays in the availability of other potentially life-saving products (eg, routine childhood vaccines and essential medicines) will be needed to advance public health and prevent excess mortality from other diseases throughout this pandemic.

Of the currently available vaccines, two require extreme storage temperatures. The Moderna vaccine requires a temperature of $-20^{\circ} \mathrm{C}$, but can be stored for up to 1 month in a regular refrigerator. Pfizer vaccine requires storage at $-70^{\circ} \mathrm{C}$ which makes transport and distribution a logistical and cost challenge for existing medical supply chains that conventionally distribute vaccines at $2^{\circ} \mathrm{C}-8^{\circ} \mathrm{C} .{ }^{4}{ }^{5}$ Getting a frozen vaccine to tens of millions of people is likely to be a far greater problem for poorer countries. For example, Peru has 30 ultracold freezers but none are available outside of Lima. These specialised freezers can take 4-6weeks to manufacture and are expensive to procure (US\$10 000-US $\$ 25$ 000). In addition, electricity sources in LMICs are often unreliable and even regular freezers like those needed to store Moderna vaccine may be scarce, potentially requiring trade-offs with storage of other vaccines.

Pfizer has developed a reusable suitcasesized container with Global Positioning System technology that can keep between 1000 and 5000 doses at ultracold temperatures for up to 10 days and an additional 5 days using regular refrigeration. This means that officials have 15 days to distribute the vaccine once it is allocated. Although vaccine containers can be topped off with dry ice every 5 days to maintain temperatures, this may be scarce in rural areas and the cost and hazards of shipping dry ice, which sublimates and turns into carbon dioxide gas, is 
a challenge. Any breach in storage temperatures could compromise the quality of precious vaccine doses. In 2011, up to 2.8 million doses of childhood vaccines were lost in five countries including Nigeria and Ethiopia due to a break in the cold chain. ${ }^{6}$ Although new technologies such as solar refrigerators are available, they have not been rolled out widely.

The 'warp speed' development and production of COVID-specific vaccine has been rightly hailed as a historic success of molecular biology, but translating this into a public health victory requires a panoply of products, the scarcity of any one of which could lead to production backlogs. From the sterile glass vials needed to turn bulk vaccine into filled and finished doses, to the calibrated needles and syringes, as well as alcohol pads and personal protective equipment (PPE) required at dispensing sites, getting jabs into arms will stress global medical staff and supply chains on which COVID-19 has already exerted unparalleled strain. Protecting the global front-line healthcare workforce, through early vaccination and provision of adequate PPE, is a critical aspect of this endeavour, especially in LMICs where any staff depletion risks jeopardising existing public health programmes (eg, other non-COVID-related vaccination campaigns).

After a vial has been punctured to take out the first dose, it must be thrown away within 6 hours. Because vaccine will be in short supply, especially at first, clinical sites will need to schedule patients so that none is wasted. This is nearly impossible in LMICs without functioning telephones and internet. In addition, many vaccines are likely to require two doses of the same vaccine, therefore the whole process must be repeated within weeks. Medical staff will need to ensure that they have enough stocks to allow the administration of booster doses, with flexibility to allow people to get their second dose in a different location if desired. This requires reliable databases to keep track of who has received what vaccine, where and when people are due for a booster. Most LMICs lack digital databases to manage patient data or reliably track vaccine inventories. Corruption, contamination and even accidental duplication will waste precious supply. In addition, about 1 billion people in the world lack formal identities and many are mobile. This presents a massive challenge for governments trying to reach a critical mass of people. Without reliable identification, it is difficult to know who has received vaccines. Biometric digital IDs are one way of overcoming this challenge but are not widely available. People getting vaccinated will therefore have to carry a COVID-19 vaccination record card that will tell them which vaccine they got, when they got it and when they should obtain their booster dose. However, this places onus in the hands of the patients with no recourse should cards get lost. Dedicated investments in a functional record-keeping and verification system will be critical to track progress, informing allocation, tailoring strategies to generate demand and provide end-to-end visibility.
In the face of these obstacles, scientific bodies such as WHO have estimated that $70 \%-80 \%$ of the population in a country will need to be vaccinated to achieve herd immunity. ${ }^{7}$ Since surveys in the USA and Hong Kong have estimated vaccine acceptance rates to be only $40 \%-70 \%$, even among healthcare providers, ${ }^{8-10}$ governments will need to develop strategic communication plans for public messaging to overcome this public scepticism. Given the level of public scrutiny for COVID-19 vaccines, even rare adverse events during roll-out could affect vaccine demand. Robust postmarketing surveillance is needed with adverse event reporting systems to monitor vaccine safety and efficacy during roll-out.

Even if demand is strong, most countries do not have robust existing adult vaccination programmes (except in rare cases, for example, tetanus for pregnant women administered through antenatal care units in Bangladesh). Mass vaccination drives will require the creation of multiple vaccination centres and new infrastructure to deliver and monitor vaccine doses. The recruitment and enrolment of vaccinators is a critical part of the process and relies on extensive collaboration between the national and local health departments, immunisation coalitions and other associations. An optimistic projection of the workforce required to administer 1 million doses daily over 100 days (the new US goal) estimated that 100000 staff—of whom 17000 are qualified to administer vaccines-would be needed. ${ }^{11}$ However, this estimate assumed what could be termed 'magical supply chain thinking' such that the underlying vaccine allocation and prioritisation strategy permitted accurate demand forecasts coordinated with the arrival of supplies at different times. Add to this is the complexity of delivery and tracking of multiple vaccines with different storage and dosing requirements, and it is easy to see how the true staffing requirements could be double or more of the modelled figures. Failure to adhere to and use existing supply chain best practices will lead to imbalances in supply and demand in specific locations and over time result in both vaccine wastage and delay in protection, causing increased morbidity and mortality, programme costs and more general economic and social losses.

In the face of such infrastructure requirements, the costs of vaccines may appear minimal, but they are not. The Pfizer and Moderna vaccines are being provided to governments at a price of US\$20-US\$37 per dose. The Oxford/AstraZeneca product is priced at US $\$ 4$ with a pledge to provide the product at a cost price to all during the pandemic, and to maintain this price for LMICs after the pandemic. Nevertheless, even this price represents a huge financial burden to many countries. Once prices start to rise, the poorest countries will be even less able to pay than they are now and there is little discussion on the use of other sources of financing, for example, from the World Bank. Without a strategic approach, coverage disparities will widen the equity gaps between HICs and LMICs. Such disparities will threaten health security and the resumption of civil society everywhere. 
To address the problem of equity, WHO, Gavi and the Coalition for Epidemic Preparedness Innovations established COVAX, a global alliance of 189 countries that have pledged to pool investment, allocate and distribute the vaccines equitably particularly in LMICs. ${ }^{12}{ }^{13}$ However, the facility is currently under-resourced and they have only been able to secure vaccines for about 250 million people. Wealthy countries are fuelling a gap in access around the world, laying claim to more than half the doses that could come to the market by the end of the year; some of the world's richest countries have even reserved enough doses to immunise their own populations multiple times over. ${ }^{14}$

Protecting the global community from the COVID-19 pandemic is not 'rocket science', it is much harder than that. Timely delivering the COVID-19 vaccine to the global population will require a strategic all-ofgovernment approach, and an unprecedented all-ofsociety approach that spans government and the private sector, crossing entrenched economic divisions between the Global North and South, as well as burgeoning antiscientific movements that threaten to scuttle dramatic advances before they can even be brought to market. Basic and applied biological science has given the world the means to tame this pandemic. To succeed now, a new set of sciences-of supply chain engineering, behavioural psychology and information management, to name only the most prominent—must be given equal representation.

Twitter Rima Shretta @rimashretta

Acknowledgements NH acknowledges the contributions of Professor John A. Muckstadt regarding supply chain engineer principles.

Contributors RS coordinated the inputs into this editorial. All authors have read and approved the final manuscript.

Funding LJW is funded by the Li Ka Shing Foundation and the COVID-19 Research Response Fund, University of Oxford.

Competing interests None declared.

Patient consent for publication Not required.

Provenance and peer review Not commissioned; internally peer reviewed.

Data availability statement There are no data in this work.

Open access This is an open access article distributed in accordance with the Creative Commons Attribution Non Commercial (CC BY-NC 4.0) license, which permits others to distribute, remix, adapt, build upon this work non-commercially, and license their derivative works on different terms, provided the original work is properly cited, appropriate credit is given, any changes made indicated, and the use is non-commercial. See: http://creativecommons.org/licenses/by-nc/4.0/.

\section{ORCID iD}

Rima Shretta http://orcid.org/0000-0001-5011-5998

\section{REFERENCES}

1 Ritchie H, Ortiz-Ospina E, Beltekian D, et al. Coronavirus (COVID-19) Vaccinations. Our World in Data. Oxford: University of Oxford, 2021. https://ourworldindata.org/covid-vaccinations

2 Zimmer C, Corum J, Wee S-L. Coronavirus Vaccine Tracker New York: New York Times, 2021. Available: https://www.nytimes.com/ interactive/2020/science/coronavirus-vaccine-tracker.html

3 DHL. Delivery of Covid-19 vaccine: DHL study shows how public and private sector can partner for success. Bonn: DHL, 2020. https:// www.dhl.com/global-en/home/press/press-archive/2020/delivery-ofcovid-19-vaccine-dhl-study-shows-how-public-and-private-sectorcan-partner-for-success.html

4 Gallagher J. Moderna: Covid vaccine shows nearly 95\% protection, 2020. https://www.bbc.com/news/health-54902908

5 Pfizer. Pfizer and Biontech announce vaccine candidate against COVID-19 achieved success in first interim analysis from phase 3 study. New York: Pfizer, 2020. https://www.pfizer.com/news/pressrelease/press-release-detail/pfizer-and-biontech-announce-vaccinecandidate-against

6 WHO Immunization Practices Advisory Committee. Immunization Supply Chain and Logistics: A neglected but essential system for national immunization programmes. 24. Geneva, 2014. https://www. who.int/immunization/documents/WHO IVB 14.05/en/

7 Lipsitch M. COVID-19 vaccines and herd immunity. Center for Communicable Disease Dynamics, Harvard TH. Chan School of Public Health, 2020. https://ccdd.hsph.harvard.edu/2020/12/17/ covid-19-vaccines-and-herd-immunity/

8 Wong MCS, Wong ELY, Huang J, et al. Acceptance of the COVID-19 vaccine based on the health belief model: a population-based survey in Hong Kong. Vaccine 2021. doi:10.1016/j.vaccine.2020.12.083. [Epub ahead of print: 20 Jan 2021].

9 Hamel L, Kirzinger A, Muñana C. KFF COVID-19 Vaccine Monitor: December 2020, 2020. https://ccdd.hsph.harvard.edu/2020/12/17/ covid-19-vaccines-and-herd-immunity/

10 Robbins R, Tavernise S, Otterman S. Cash, Breakfasts and Firings: An All-Out Push to Vaccinate Wary Medical Workers. New York Times 2021 January 14, 2021. Available: https://www.nytimes.com/ 2021/01/14/business/covid-vaccine-health-hospitals.html?auth= login-email\&login=email

11 Bollyky T, Nuzzo J, Baccam P. How to Distribute 100 Million Vaccine Doses in 100 Days. New York Times 2021 January 20, 2021. https:// www.nytimes.com/2021/01/20/opinion/covid-vaccine-biden.html? action=click\&module=Opinion\&pgtype=Homepage

12 UN News. COVID-19 vaccines: donors urged to step up funding for needy countries. New York: UN News, 2020. https://news.un.org/en/ story/2020/12/1079842

13 WHO. Fair allocation mechanism for COVID-19 vaccines through the COVAX facility. Geneva: WHO, 2020. https://www.who.int/ publications/m/item/fair-allocation-mechanism-for-covid-19vaccines-through-the-covax-facility.

14 Twohey M, Collins K, Thomas K. With First Dibs on Vaccines, Rich Countries Have 'Cleared the Shelves'. New York Times 2020 December 15, 2020. https://www.nytimes.com/2020/12/15/us/ coronavirus-vaccine-doses-reserved.html 